\title{
Green supply chain management in construction: A systematic literature review and future research agenda
}

\section{Abstract}

The construction industry is responsible for significant environmental impact. Mounting ecological and societal concerns are driving construction to 'go green'. Green supply chain management offers the potential of a systemic approach to facilitate transformation of the sector. Research on green supply chain management in construction has been growing in recent times but to date has not been systematically brought together. A systematic literature review (SLR) is presented, applying the high standards of rigour and transparency required by the methodology. From an initial search result of 207 papers, 44 were included in the detailed analysis. The papers are described in terms of publication outlet, date of publication, geographic setting, methods used, tools and techniques, conceptual definition, the role of stakeholders and practical implications. The findings are synthesized to propose a categorization of approach and a comprehensive definition of green supply chain management in construction. An agenda for future research is outlined which emphasizes the need for an end-to-end perspective, engagement with the unique characteristics of the industry, a focus on the ultimate goals of environmental sustainability, and on gaps in practical guidance, use of insights from relevant theoretical perspectives, and expansion to include critical stances.

Keywords: construction industry; green supply chain management; sustainable supply chain management; systematic literature review

\section{Introduction}

Societies across the globe are experiencing unprecedented circumstances as a direct consequence of environmental degradation, resource depletion and climate change. As a result, there are growing calls around the world for transformative change in how humans and businesses interact with the natural environment. The construction industry is a major consumer of the world's resources and energy (Lucon et al., 2014), used for the delivery of the built environment and in the operation of buildings and infrastructure. The construction 
sector is seen as amongst the most environmentally damaging of industries, accountable for $30 \%$ of solid waste in the European Union (European Union, 2015). Construction and demolition waste is particularly damaging to the environment due to its large volume, weight and heterogeneous nature. Globally, the construction industry is also responsible for consuming about one-third of the world's resources which includes consuming $36 \%$ of its energy and producing 39\% of greenhouse gases (GHG) (UN Environment, 2017). Embodied carbon emissions are found to contribute an increasing share of a project's whole life carbon emissions, as work to reduce operational emissions bears fruit (Ibn-Mohammed et al., 2013). Furthermore, the energy consumption of buildings and the resources used are 'locked-in', potentially for decades (Lucon et al., 2014), before the building is taken out of use, demolished, and its constituent elements either become available for re-use or recycling, or end up as waste.

The negative environmental impacts of the construction industry have been recognized around the world and strict environmental regulations have been introduced by governments to curb the environmental damage caused by construction operations. A regional example of such governmental efforts is that of European Union directives on waste reduction, while a national example is found in the UK's energy efficiency requirements in building regulations. Exemplary initiatives globally include the United Arab Emirates' ambitious Masdar project of developing a city that is powered exclusively by clean energy, as well as New York City's emissions caps for large buildings (Martin, 2017). A key target of Construction 2025, the UK Government's strategy for construction, is a $50 \%$ reduction in GHG emissions from the built environment by 2025, compared to a 1990 baseline (HM Government, 2013). International environmental management systems standards such as ISO 14001, and environmental performance assessments such as BREEAM, LEED and Estidama have also witnessed wider adoption across the world as guidelines for constructing and operating buildings more sustainably. More than 70 national Green Building Councils have been established worldwide to offer advice to the stakeholders involved, as well as to coordinate sustainability efforts and provide leadership. Innovative environmental products and processes such as laminated timber products, lime mortar and render, natural insulation materials and pre-fabrication processes are also gaining popularity and wider use. In addition, and highly pertinent to today's construction industry is the Paris Agreement at the United Nations Climate Change Conference, signed by 195 countries as of July 2018 (Climate Analytics, 2018), establishing the first legally binding global climate deal with the objective of holding global average temperature increase to "well below $2{ }^{\circ} \mathrm{C}$ above pre-industrial levels" (United Nations, 2015). This has significant implications for the construction industry, particularly the need for construction firms to meet sectoral, national and international GHG reduction commitments.

Underpinned by a construction improvement agenda (HM Government, 2013) and innovative management practices, supply chain management (SCM) has increasingly been pursued by firms in the construction industry (Fulford \& Standing, 2014). A construction supply chain encompasses all of the organizations involved in the delivery of the built asset to the client. These organizations are engaged in upstream and downstream flows of products, services, finances, and information, from the manufacturer through to the supplier, subcontractor, 
main contractor, client and in some cases to the construction end user, and the building occupant (Pryke, 2009). SCM is a management approach that is dedicated to developing processes, practices, tools and techniques that increase operational efficiency and effectiveness throughout this delivery chain (Irizarry et al. 2013; Saad et al., 2002; Vrijhoef \& Koskela, 2000). SCM in construction has tended to be driven by main contractors pursuing long-term relationships with large construction clients, with the benefits to main contractors including managing market volatility and enhancing profitability (Alderman and Ivory, 2007; Ive and Murray, 2013).

The Intergovernmental Panel on Climate Change has stressed the need for methods to enhance collaboration across the construction supply chain, in order to expedite progress (IPCC, 2012) and Green SCM offers such a system-level approach. Driven by awareness of environmental impact and policy pressures as described above, the concept of Green SCM has emerged in research and practice. The development of Green SCM research began in the 1990s with scholarly work such as that of Walton et al., (1998) and has been developing alongside other environmental ideas such as that of the circular economy adopted from industrial ecology (Ehrenfeld, 1995). Green SCM is fundamentally about the integration of environmental considerations into the supply chain, including the reduction of material flows and the minimization of inadvertent negative consequences of the processes of production and consumption (Sarkis et al., 2011). The embedding of environmental objectives alongside the concepts from SCM of inter-firm collaboration, process integration and relationship management offers a conceptual approach which could facilitate the transformation required of the industry.

Given the importance of addressing the construction industry's adverse effects on the environment, and in the wake of the Paris Agreement, the paper provides a state-of-the-art review of existing research on Green SCM in construction to ask: where are we now and what needs to be done? The construction sector is unique structurally and relationally (as discussed further below) and a systematic review of Green SCM in construction remains to be published. The aim of this paper is twofold: First, it presents a systematic review of the literature on Green SCM in the construction industry considering papers published up to August 2017, to provide a description and synthesis of their findings. Second, based on the gaps identified in the extant literature, an agenda for future research is proposed.

The structure of the paper is as follows. The methodology of the systematic literature review is first described, followed by a descriptive analysis of the core set of papers is presented. A synthesis of findings is developed and finally an agenda for future research is proposed.

\section{Research Methodology}

To identify the state-of-the-art in Green SCM in construction, and to integrate published 
scholarly work on the topic, a systematic literature review was conducted. Originating in health research, systematic literature reviews are increasingly employed in other research domains where a comprehensive review can contribute to knowledge (Briner \& Denyer, 2012). A systematic review may be distinguished from a non-systematic or expert review by its focus on transparency and rigour. An expert review may lack an explicit statement of the search strategy or the protocol used to identify the relevant literature. An expert review may provide limited clarity on the processes of selection of papers, evaluation of the quality of papers, and of the criteria for inclusion or exclusion of specific studies. As Gough and colleagues (2012) noted, this means that it can be unclear in a non-systematic review if a particular paper has been omitted through oversight or through conscious exclusion on an unexplained basis. Where an expert review is not always comprehensive or methodical, a systematic review is a structured, transparent and reproducible method for reviewing research which uses specified and documented processes in the identification, selection and critical assessment of the searched literature (Gough et al., 2012). The approach supports a high level of objectivity, in both method and analysis, as well as replicability, and can provide a comprehensive account of published scholarly work in a field of study.

In their book developed from extensive experience of systematic reviews across a range of domains, Gough, Oliver and Thomas (2012) recommend a set of stages for an SLR. We adopted their recommendations for the study. Table 1 summarizes the protocol for the current review.

\section{Table 1 Systematic review protocol}

\begin{tabular}{|l|l|l|}
\hline Stage & Stage & Description for the current study \\
\hline 1 & $\begin{array}{l}\text { Define the research questions } \\
\text { and definitions }\end{array}$ & $\begin{array}{l}\text { What is the status of research on Green SCM in construction? } \\
\text { What are the key theoretical and practical insights? }\end{array}$ \\
\hline 2 & $\begin{array}{l}\text { Define the exclusion/eligibility } \\
\text { criteria }\end{array}$ & $\begin{array}{l}\text { a) Paper in English } \\
\text { b) Published in a peer-reviewed journal } \\
\text { c) Published before } 31^{\text {st }} \text { August } 2017 \\
\text { d) Paper topic is green supply chain management } \\
\text { e) The paper focus is the construction sector }\end{array}$ \\
\hline 3 & Define search terms and sources & $\begin{array}{l}\text { Search terms: supply chain AND (green OR sustainable) AND } \\
\text { construction IN subject } \\
\text { Sources: see below }\end{array}$ \\
\hline 4 & The map & Search, screen and compile set of included studies \\
\hline 5 & The analysis & $\begin{array}{l}\text { Code and critically evaluate included studies. Table } 2 \text { presents } \\
\text { the coding structure. }\end{array}$ \\
\hline 6 & The synthesis & $\begin{array}{l}\text { Integrate patterns across key themes; formulate future research } \\
\text { agenda. }\end{array}$ \\
\hline
\end{tabular}

It is worth noting the distinction between Green SCM and Sustainable SCM: the two terms are sometimes used interchangeably (and so were used in initial selection), but the meanings are not synonymous. Green SCM considers the impact of supply chains on the natural environment, in terms of the energy they consume, the materials they use and the waste they generate. Sustainable SCM encompasses a wider perspective, which considers not only 
environmental issues, but also social and economic (Ahi \& Searcy 2013; Pagell \& Shevchenko 2014). Here the topic was Green SCM - a more focused concern but one from which the findings may also be valuable to the broader sustainability agenda. The study began with an initial definition of Green SCM in construction as all initiatives aimed at reducing the environmental impact of the supply chain for the built environment. This definition is refined and elaborated below.

To ensure the widest range of possible sources, a structured keyword search was conducted using Explore, a proprietary front-end populated with meta-data from over 500 sources, including major publishers, learned societies and institutional repositories such as Scopus, Web of Science, ProQuest, National Academy of Sciences, Elsevier, Palgrave Macmillan, Taylor \& Francis, Springer Link, Nature, Sage and Academic Press, together with institutional repositories including the Universities of California, Cambridge and Edinburgh. An additional search was also made in a specialist construction database compiled by ARCOM (Association of Researchers in Construction Management).

Initial screening of papers showed the fuzzy boundaries of the topic of Green SCM in the literature which presented a challenge in determining the final dataset. For example, are waste management, cement production, green procurement or reverse logistics within the domain? The default decision was 'inclusion' if the paper was found from the search terms above, as the original authors deemed their work as relevant to Green SCM in construction through their choice of keywords or phraseology. Where a paper focused on a particular construction material, the decision was to include it provided that the research or discussion crossed stakeholder boundaries and included the perspectives of different supply chain actors. This applied also to studies focusing on waste management. Papers on lifecycle analysis (LCA) of materials or products were included as the technique examines different stages along the supply chain. The focus on Green SCM meant excluding related topics such as environmental management systems, environmental performance and the social aspects of sustainability. The initial search yielded 207 papers with 44 papers finally selected for detailed analysis. These 44 papers are referred to as the core dataset below.

The initial coding structure comprised: location, focus, method, aim and findings. Emergent themes were added as the analysis progressed and comprised: tools and techniques, definition, stakeholders, practical implications and stage of supply chain ). Analysis proceeded by coding themes: a summary was produced for each theme. The themes of aim and findings were highly varied and detailed, and the summaries were inadequate to represent the range and detail. The remaining themes however permitted useful abstraction of the main contribution of the papers and analysis was continued on the themes listed in Table 2. The summaries were then integrated into an initial synthesis which drew out the main topics, gaps and areas for future research. This overview was then checked back to the papers in a second, detailed review. The thematic summaries were extended, the overview findings were refined, and the future agenda was expanded into greater depth to provide the final synthesis. 
Table 2 Coding structure

\begin{tabular}{|l|l|}
\hline 1 & Location - date, geographic setting, journal \\
\hline 2 & Method - case study, mixed, quantitative, qualitative or other \\
\hline 3 & Tools \& techniques - e.g. decision-making, environmental regulation \\
\hline 4 & Definition of SCM, Green SCM or Sustainable SCM \\
\hline 5 & Stakeholders - including responsibilities of stakeholders \\
\hline 6 & Practical implications \\
\hline 7 & Paper focus - construction industry generic or specific (e.g. road maintenance, residential) \\
\hline 8 & Stage - planning, design, procurement, construction, operation, demolition, disposal \\
\hline
\end{tabular}

To ensure rigour, several strategies were adopted. Relying only on the judgments made by a sole researcher may weaken the validity and reliability of the review (Brewerton and Millward, 2001). Hence, the involvement of two or more analysts is recommended, particularly during the data collection and analysis stages (Gough et al., 2012). To improve validity and consistency, both authors independently conducted the search and assessed the papers for inclusion in two stages: (a) reviewing title, keywords and abstract; and (b) skim reading of the paper. At each stage, the two researchers compared their decisions for agreement and any discrepancies were either resolved or the default invoked of inclusion to the next stage. The cross-validation continued during the analysis and synthesis stages. To ensure transparency and accountability, there was a priori specification of the research questions, the search criteria, criteria for inclusion and exclusion, and the stages in analysis and synthesis.

\section{Descriptive Analysis}

This section discusses the findings of coding themes 1 to 6 (see table 2).

\subsection{Distribution across time, geographic locations and journals}

Scholarly interest in Green SCM in general has been traced back to the early 1990s (Zhu \& Sarkis 2006). However, the findings indicate that the importance of the topic has lagged in construction management research, with the earliest paper in the dataset being published as recently as the year 2000. Since then, the concept has steadily gained momentum from only $16 \%$ of the papers being published up to and including 2011, interest increasing in 2012, and a more dramatic upturn in 2016 and 2017 (see Fig. 1). 
Figure 1: Distribution of reviewed papers according to year of publication

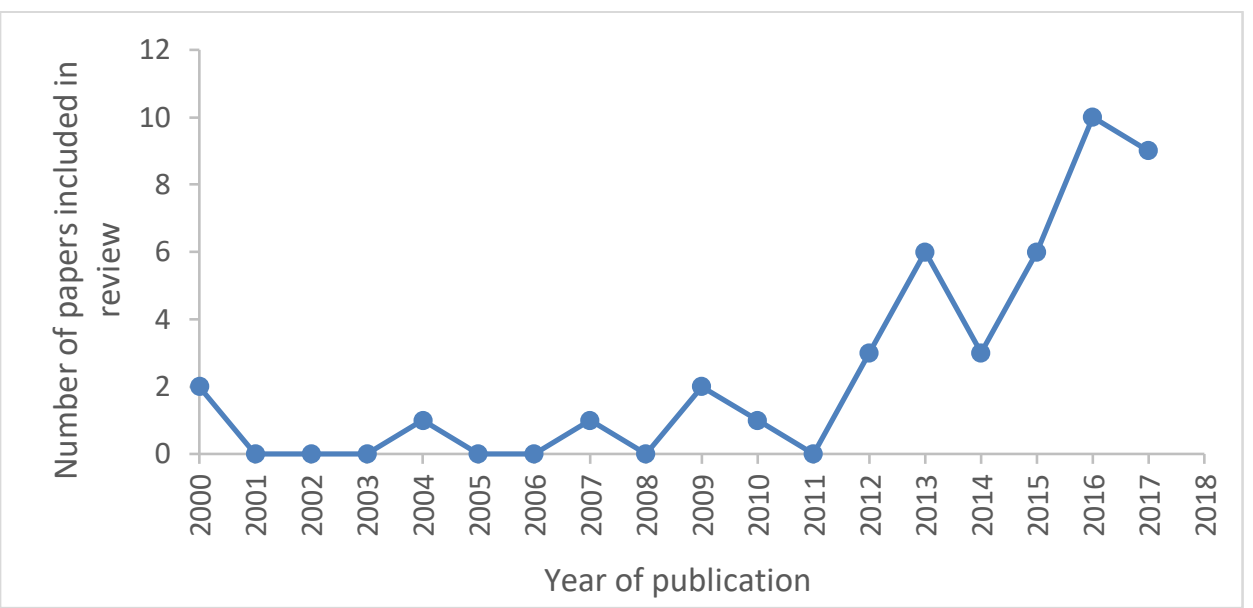

Note: the 2018 total is partial (up to $31^{\text {st }}$ August 2081)

The growing recognition of the topic is also evidenced by the wide range and multidisciplinary nature of the publication outlets of the 44 papers in the dataset. Papers were published in journals such as Waste Management, Resource Policy, and Building Research and Information. In total, thirty-one (31) journals published the core papers, with only four publications including multiple papers on the topic: ten papers were published in the Journal of Cleaner Production, three papers in Sustainability (Switzerland), two papers in the Journal of Construction Engineering and Management, and two papers in WIT Transactions on Ecology and Environment.

The papers also provided a wide geographic spread (see Fig 2). However, it is notable that only one study was undertaken in South America and there is a paucity of research representing sub-Saharan Africa. This points to a gap in empirical evidence in the global south. 
Figure 2: Geographic distribution

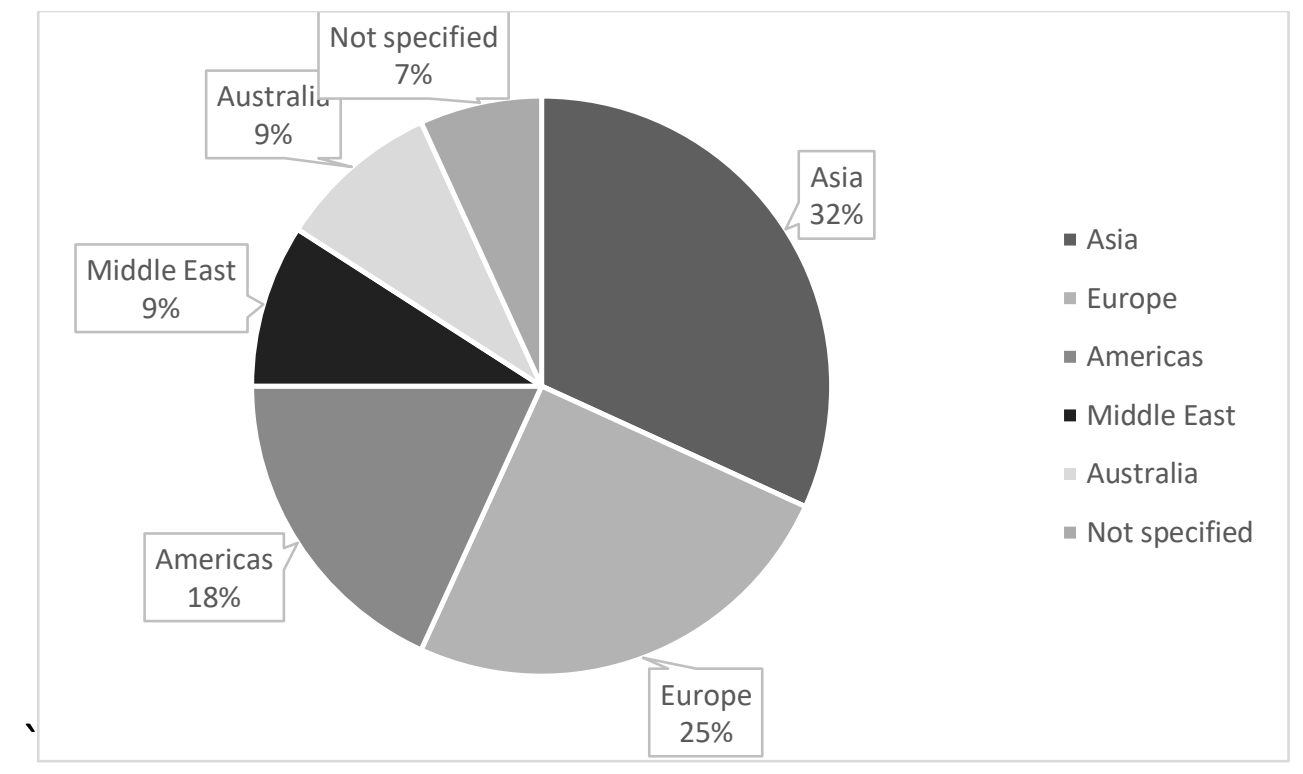

The coding for focus and stage (codes 2 and 3 in Table 2) showed wide heterogeneity and, rather than a brief description in this section, are analyzed in Section 4.

\subsection{Methods applied}

A variety of methods were used to examine the concept of Green SCM, offering a generally strong methodological grounding for their findings. Specialized quantitative methods were applied in 15 papers, including Life Cycle Analysis (LCA) (Kucukvar et al., 2014), material flow analysis (Chen et al., 2017), and organizational environmental footprint (Neppach et al., 2017). The work of Balasubramanian (2014) is notable in that the rigorous quantitative approach of structural modelling was employed to ascertain the factors driving the organizational adoption of Green SCM in the UAE construction industry. A variety of other research methods were adopted across the core papers, including survey questionnaires (6 papers) qualitative interviews (5), case studies (6), and mixed methods (5). Those adopting a survey approach collected between 39 and 455 responses suitable for analysis. In most of the papers applying a qualitative method, the number of cases was sufficient for robust analysis, with up to 31 interview participants involved. Case study research can be particularly valuable in exploring Green SCM in construction as it can shed the light on contextual issues to a greater extent than other empirical approaches and six studies adopted this method. Although action research could yield particularly interesting insights into environmental issues in SCM (Seuring \& Gold 2013), offering the potential for mutual learning between practitioners and academics, it is noteworthy that only one paper from the core set adopted this approach (Uttam \& Le Lann Roos, 2015). 
The studies reviewed, therefore, were mostly based on robust empirical data. There were a few exceptions, however, that made it difficult to assess the methodological rigor of the studies, including two qualitative studies with low numbers of interviewees: 4 and 6 respectively in Bohari et al. (2017) and Elbarkouky \& Abdelazeem (2013), and a paper that did not provide information on the number of interviews upon which the results are based (Zuo et al., 2009).

\subsection{Tools and techniques for Green SCM in construction}

Specialised tools and techniques were proposed in nearly one third of the papers, including lifecycle analysis (LCA) (7), complex decision-making techniques (3) such as Choosing By Advantages (CBA) and Technique for Order of Preference by Similarity to Ideal Solution (TOPSIS), Sankey diagrams (1) and organizational environmental footprinting (1). External frameworks (environmental certification, regulation) were discussed in three (3) papers and internal organizational or management approaches were the focus of a further five (5). These papers considered the business model (1), alliances and supplier integration (2), critical success factors and performance measures (1) and lean methods such as $3 R$ and $5 S$ (1). In addition to the tools and techniques mentioned, a few papers provided extensive lists of what they termed 'enablers' (Balasubramanian (2014; Seth et al 2016; Wong et al 2016). These listed terms such as 'process management' and 'corporate factors' such as management commitment. However, no clear definition was found of what constitutes 'enablers' and their distinguishing characteristics.

\subsection{Definitions of Green SCM in construction}

The majority of papers in the dataset did not attempt to define Green SCM in construction. Most of the papers that focused on secondary SCM concepts offered definitions of these, for example: green manufacturing (Seth et al., 2016), green procurement (Shen et al., 2017), sustainable supply mix and sustainable materials management (Chen et al. 2017), sustainable or lean construction (Sertyesilisik, 2016), waste management (Kucukvar et al. 2016), and reverse logistics (Chileshe et al., 2016). Balasubramanian (2014) proposed that Green SCM in construction is based on three dimensions: environmental, economic and operational performance, and these may also be interpreted as dimensions for evaluation. Where definitions of Green SCM were provided by the authors, the majority assumed an operational stance, describing the processes involved. Adawiyah et al. (2015:1020) for example proposed that Green SCM comprises "green purchasing, green manufacturing, green distribution (marketing) and reverse logistics". Taking a broader perspective, Da Rocha and Sattler (2009) drew on definitions of SCM from Ballou et al. (2000) as the activities involved in the flow of goods or services from primary source to the end-client. The same paper also included reference to Lambert and Cooper's (2000) definition of SCM as the integration of the main processes between suppliers and end clients to add value for stakeholders. The latter usefully 
draws attention to a strategic business objective of SCM - that of adding value. However, the definition is quite narrow in its limitation to integrated processes: this omits critical aspects of SCM such as developing inter-organizational relationships.

Several papers, though not all, considered the objectives of Green SCM. These were argued to be: increasing the competitive advantage of a firm (Woo et al., 2016), providing stakeholders with added value (Da Rocha \& Sattler, 2009), improving the performance of a supply chain ecologically, economically and operationally (Balasubramanian, 2014), enhancing the sustainability of supply, improving service and increasing market share (Adawiyah et al., 2015), increasing the efficiency of operations, reducing costs and risks, and for ethical considerations (Dadhich et al., 2015), and reducing adverse environmental effects (Balasubramanian \& Shukla,2017b).

Unexpectedly, only a limited number of papers in the core sample took a more conceptual viewpoint of Green SCM. A few authors recognised the holistic, end-to-end conceptualisation of green supply (Da Rocha \& Sattler, 2009; Balasubramanian \& Shukla 2017a) and underlined the role of greater client-supplier process integration (Da Rocha \& Sattler, 2009; Zhou et al., 2013), as well as green practices being assimilated into business processes (Balasubramanian 2014; Balasubramanian \& Shukla, 2017b; Nasir et al., 2017) and inter-organisational SCM (Ketikidis et al., 2013). The findings here of a failure in construction management research to consider business sustainability principles mirror those of an earlier paper. Specifically, Ahi and Searcy (2013) underlined the lack of emphasis on stakeholders and the absence of a longterm view to greening the supply chain in the wider Green SCM literature.

\subsection{Stakeholders}

The construction supply chain is diverse, complex and could involve not only hundreds but thousands of actors engaged in dyadic, short-term supply chain relationships. The core papers generally reflected this complexity to some extent, with reference made to a variety of supply chain actors including construction clients and developers (10), construction professionals including architect/designers, engineers, project managers and specialist subcontractors (15), main contractors (4), as well as the expected suppliers and logistics operators mentioned by most. However, one-third of the core papers failed to consider the role of stakeholders - a notable weakness in the literature reviewed. The papers in the review reflected a divergent view on the level of commitment and motivation of the multiple stakeholder roles. The role of the construction client/developer as a catalyst for environmentalism was argued by some (Udawatta et al., 2015). The role of designers was underlined as important given their influence over the choice of material and the final product design (Albino \& Berardi, 2012; Arroyo et al, 2016; Sertyesilisik, 2016), although Wong et al. (2016) noted that designers may have limited incentives to collaborate fully in green supply chains.

In coding for stakeholders in the analysis, the core papers were assessed on how they engaged with and reflected upon the particular characteristics of the construction industry. Nearly all 
the papers introduced their research topic by first underlining the considerable negative environmental impacts of the construction industry, but it is notable that only a few of the papers extended this to build a picture of the unique nature of the industry. Fragmentation was mentioned by Dainty \& Brooke (2004) and Aho (2013), while Arroyo et al. (2016) and Neppach et al. (2017) considered the complexity of projects and the multiple stakeholders involved. A few papers considered the structure and processes of construction systems (Sertyesilisik, 2016; Wong et al., 2016). Balasubramanian and Shukla (2017a, b) discussed the project-based operational processes of construction and the large number of firms involved in short-term, dyadic contractual relationships. In addition, the inherent uncertainty, instability, and slowness of change in the construction industry were underlined by Albino \& Berardi (2012). The industry's contractual arrangements were seen as deficient from the ideal models of SCM, particularly as contractors and suppliers are often reluctant to develop and adopt innovative approaches because benefits of these are perceived to be realized exclusively by clients (Albino \& Berardi, 2012).

\subsection{Practical implications of Green SCM in construction}

Several practical recommendations for managers and policy makers were offered by the papers reviewed. Supply chain managers in construction can lower environmental impact through operational changes such as eco-design (Sertyesilisik, 2016), adopting environmental standards (Bohari et al., 2017), purchasing sustainably (Shen et al., 2017), and adopting practices that include recycling and closed-loop systems (Chileshe et al., 2016), as well as considering environmental impact in measuring their performance and in managing risk (Zou \& Couani, 2012).

Amendments to construction contracts are needed to support green procurement such as the inclusion of green requirements in tendering for design and in selecting contractors and operators, as well as including environmental elements in bid evaluation and pre-qualification criteria (Sertyesilisik, 2016). Warranties which cover green innovations that may entail greater risks may be required (Albino \& Berardi, 2012). Green SCM also necessitates the availability of sufficient strategic and operational management capabilities and extended commitment in overseeing the successful transition to new ways of working (Dainty \& Brooke, 2004), in addition to cultural change (Sertyesilisik, 2016). Sustainability expertise is vital (Chen et al, 2015) and could be contracted for a project (Bohari et al, 2017). In alignment with understanding in the general literature on SCM on the importance of relationships, a small subset of the core papers addressed the management of relationships in construction supply chains. The potential was considered for greater integration among supply chain actors through the establishment of strong relationships that can enhance trust, such as alliances (Dainty \& Brook, 2004; Da Rocha \& Sattler, 2009), and co-makership (Albino \& Berardi, 2012). There has been a discussion too of the need for greater alignment of perceptions of value and performance among supply chain firms (Aho, 2013). 
Greater understanding of contextual issues when implementing Green SCM was emphasized by several papers, including the geographic context (Blengini \& Garbarino, 2010), and the social and economic contexts (Da Rocha \& Sattler, 2009). New business models could be introduced that enable greater alignment between pricing and the value accrued by clients and the wider society (Aho, 2013). The role of regulation and standards have been described as pivotal in driving change with regulation signalling the commitment of governments to the environmental agenda, and standards offering guidance and benchmarks (Bohari et al., 2017). To support Green SCM in construction, comprehensive green procurement standards have been argued to be necessary as well as industry certification programs, and publicly available databases could facilitate accessibility to product environmental performance data as well as exemplars of successful Green SCM in construction (Wong et al., 2016).

\section{Synthesis}

Having presented the main findings under theme headings in Section 3, this section advances three topics for further discussion: systematic classification of the literature, comprehensive definition of Green SMC in construction, and theoretical framing. The three topics emerged from the foregoing analysis as important for further development of the domain.

\subsection{Classification}

The wide range of journals in which the papers were published indicates the heterogeneous nature of the studies. To aid description and analysis of the field, we sought an appropriate classification of the papers. Based on the themes of focus and stage (the final two themes in Table 2), we created a two by two matrix which offered a useful scorecard to assess coverage. The first dimension on the matrix considered whether the paper addressed Green SCM as a holistic concept ('Holistic'), considering multiple management processes around materials, information and financial flows, versus focusing on a specific process such as procurement or waste management ('Functional'). The second dimension considered whether the paper addressed the construction industry in general ('Construction generic') versus a focus on a specific subdomain such as a material (cement, aggregate, etc.), subsector (e.g. residential) or stakeholder (e.g. a major contractor).

Papers which addressed generic construction at a functional level examined:
A. procurement (6 papers),
B. waste management including reverse logistics (4),
C. decision-making in purchasing (1),
D. materials management (1) and 
E. information exchange (1).

Papers taking a functional view on a construction subdomain investigated:

F. decision-making in purchasing (4 papers),

G. waste management (3),

H. procurement (3),

I. manufacture and product certification (2),

J. information exchange (1) and

K. supplier environmental capability (1).

The subdomains comprised:

i. major contractors and suppliers (3 papers),

ii. residential construction (2),

iii. timber (2),

iv. aggregate and minerals (2),

v. specific projects (2),

vi. ceiling tiles (1),

vii. cement (1) and

viii. roads (1).

The papers which took a holistic view of Green SCM in a particular subdomain examined:

ix. aggregate (1 paper)

x. plasterboard (1)

xi. comparison of GSMC by subsector within construction (2) and

xii. residential construction (1).

As the field develops, it may be useful to further categorize within construction subdomains but a simple two by two matrix appeared adequate at this stage to map coverage and identify the quadrant(s) with less research attention to date. Table 3 presents the scorecard, with papers listed in chronological order, indexed in square brackets with reference to the classification lists above. Cell 1 requires no indexes as the papers address holistic approaches across construction generically. 
Table 3: Coverage scorecard

\begin{tabular}{|l|l|l|}
\hline & Holistic & Functional \\
\hline & Zou \& Couani (2012) & Ofori (200) [A] \\
& Aho (2013) & Dainty \& Brooke (2004) [B] \\
& Elbarkouky \& Abdelazeem (2013) & Sarkis et al. (2012) [C] \\
& Ketikidis et al. (2013) & Mahamadu et al. (2013) [E] \\
& Zhou et al. (2013) & Kucukvar et al. (2014) [B] \\
& Balasubramanian (2014) & Ruparathna \& Hewage (2015) [A] \\
& Adawiyah et al. (2015) & Udawatta et al. (2015) [B] \\
& Sertyesilisik (2016) & Chileshe et al. (2016) [B] \\
& Neppach et al. (2017) & Wong et al. (2016) [A] \\
& Nasir et al. (2017) & Ahmadian et al. (2017) [A] \\
& Balasubramanian \& Shukla (2017a) & Bohari et al. (2017) [A] \\
& Balasubramanian \& Shukla (2017b) & Chen et al. (2017) [D] \\
& & Shen, Zhang \& Zhang (2017) [A] \\
& & \\
\hline \multirow{5}{*}{ Generic construction } & Hendrickson \& Horvath (2000) [xi] & Irland (2007) [I-iii] \\
& Albino \& Berardi (2012) [xii] & da Rocha \& Sattler (2009) [G-ii] \\
& Dadhich et al. (2015) [x] & Zuo et al. (2009) [H-iii] \\
& Faleschini et al. (2016) [ix] & Blengini \& Garbarino (2010) [G-iv] \\
& Abdul Ghani et al. (2017) [xi] & Hsueh \& Yan (2013) [F-i] \\
& & Rizzi et al. (2014) [H-viii] \\
& & Chen et al. (2015) [F-iv] \\
& & Uttam \& Le Lann Roos (2015) [H-v] \\
& & Arroyo et al. (2016) [F-vi] \\
& & Seth et al. (2016) [I-vii] \\
& & Kim et al. (2016) [K-i] \\
& & Kucukvar et al. (2016) [G-v] \\
& & Salzer et al. (2016) [F-iii] \\
& & Woo et al. (2016) [J-i] \\
\hline
\end{tabular}

\subsection{A comprehensive definition of Green SCM in construction}

Section 3.4 discussed the limitations in definitions of Green SCM in the core papers. To address this gap, we offer a comprehensive definition of Green SCM in construction. This is grounded in the definitions summarised in Section 3.4 and a sample reference is provide for each point.

For an organization in construction, Green SCM comprises the management of all activities related to minimizing the environmental impact of all its supply chains which contribute to its final products (Da Rocha \& Sattler, 2009), with the aim of achieving zero net harm to the environment (CIEEM, 2018; United Nations Environment, 2018). The objectives of Green SCM consist of improved environmental performance (Balasubramanian \& Shukla, 2014b), and 
improved business performance through greater efficiency, increased competitiveness and increased value to stakeholders (Woo et al., 2016). The activities comprise, at a minimum:

1. Green purchasing and procurement (Shen et al., 2017): using environmental criteria and assessment tools in evaluating and choosing products and services based on their environmental performance.

For different actors in the supply chain, Green SMC in construction can additionally include:

2. Green design (Sertyesilisik, 2016): designing environmentally-friendly construction products in terms of the material used, the production process, and the product-inuse consumption of resources and toxicity.

3. Green manufacturing (Seth et al., 2016): limiting the adverse environmental effects of the manufacturing process through consideration of energy use, water consumption, and toxicity with consideration of the design of the production process and packaging of goods.

4. Green logistics (Adawiyah et al., 2015): reducing transportation-related environmental impacts by considering the distance travelled, the number of journeys, the volume and weight of goods, and fuel consumption.

5. Waste management (Kucukvar et al. 2016): reducing the use of resources and increasing the re-use of recycled material.

6. Green operation (Balasubramanian, 2014): reducing environmental harm during the product's use by considering its energy and water efficiency.

7. End-of-life management (Chileshe et al., 2016): maximizing a product's materials' reuse through reverse logistics and circular economy principles.

Green SCM in construction requires management of these activities to achieve the required objectives (Sertyesilisik, 2016), that is, strategic direction, planning, control, measurement, monitoring and evaluation. The activities, objectives and management of Green SCM will vary by the role of the firm, as discussed below. Successful Green SCM requires relationship management as part of the greater integration of business processes and systems along supply chains (Ahi \& Searcy, 2013).

The work of Balasubramanian and Shukla (2017a) pointed to the value in mapping between role and activities. Their research linked detailed green practices, drivers and barriers to four roles: developers, contractors, architects/consultants and suppliers. Noting from da Rocha \& Sattler (2009) the importance of consideration of sub-contractors and from work on materials (e.g. Seth et al., 2016), the importance of manufacturers, we extended the list of roles to six. Based on our reading of the core papers, Table 4 presents a proposed alignment between supply chain roles and Green SCM activities. 
Table 4: Construction supply chain role and primary Green SCM activities

\begin{tabular}{|l|l|l|l|l|l|l|}
\hline & Client & $\begin{array}{l}\text { Major } \\
\text { contractor }\end{array}$ & $\begin{array}{l}\text { Design } \\
\text { team }\end{array}$ & $\begin{array}{l}\text { Sub- } \\
\text { contractors }\end{array}$ & $\begin{array}{l}\text { Materials } \\
\text { suppliers }\end{array}$ & $\begin{array}{l}\text { Materials } \\
\text { manufacturers }\end{array}$ \\
\hline $\begin{array}{l}\text { Green } \\
\text { purchasing }\end{array}$ & $\mathrm{X}$ & $\mathrm{X}$ & $\mathrm{X}$ & $\mathrm{X}$ & $\mathrm{X}$ & $\mathrm{X}$ \\
\hline Green design & & & $\mathrm{X}$ & & & $\mathrm{X}$ \\
\hline $\begin{array}{l}\text { Green } \\
\text { manufacturing }\end{array}$ & & & & & $\mathrm{X}$ \\
\hline Green logistics & & & $\mathrm{X}$ & $\mathrm{X}$ & $\mathrm{X}$ & $\mathrm{X}$ \\
\hline $\begin{array}{l}\text { Waste } \\
\text { management }\end{array}$ & & & $\mathrm{X}$ & $\mathrm{X}$ & $\mathrm{X}$ & $\mathrm{X}$ \\
\hline $\begin{array}{l}\text { Green } \\
\text { operation }\end{array}$ & $\mathrm{X}$ & & $\mathrm{X}$ & & & \\
\hline $\begin{array}{l}\text { End-of-life } \\
\text { management }\end{array}$ & & & $\mathrm{X}$ & & & $\mathrm{X}$ \\
\hline
\end{tabular}

\subsection{Theoretical framing}

Given that Green SCM is a form of SCM (Ahi \& Searcy, 2013), our expectation was that the research papers would draw extensively on established SCM work to inform their studies theoretically. However, this was not the case. Use of the SCM literature was generally limited although a few papers harnessed previous insights, including an end-to-end perspective and the importance of trust to facilitate inter-firm integration (da Rocha \& Sattler, 2009), issues of supply chain integration (Ofori, 2000) and the importance of co-makers in innovation (Albino \& Berardi, 2012). Beyond the limited use of previous work on SCM, the absence of theoretical frameworks for Green SCM was a visible weakness in the literature surveyed, with a few exceptions. Where studies examined ancillary concepts such as green procurement and reverse logistics, some frameworks were suggested. Sertyesilisik (2016) proposed extending Porter's diamond framework of factors influencing competitiveness (Porter, 1998) to include requirements of future generations and broader 'sustainability conditions' Balasubramanian and Shukla (2017a) critiqued earlier theoretical frameworks of Seuring and Müller (2008a, b) and Carter and Rogers (2008) as not comprehensive and no longer up-to-date. They went on to offer the only new theoretical framework proposed for Green SCM in the papers reviewed (Balasubramanian, 2014; Balasubramanian and Shukla 2017a). Deriving first a quadrantbased categorisation of enablers of Green SCM, based on an extensive review of the Green SCM literature (Balasubramanian, 2014), Balasubramanian and Shukla (2017a) proposed and tested a nine-construct structural model, in which they demonstrated the relationship between internal and external drivers and barriers to core and facilitating green practices, and the relationship between core and facilitating green practices and environmental, economic and organisational performance. Further, they tested these relationships for four main roles in construction (developer/client; architect/designer; major contractor; material suppliers). In our view, this represents an important step forward in the literature by offering a tested framework which future research can seek to apply or extend. 


\section{Future research agenda}

The preceding sections have described and analyzed existing research on Green SCM in the construction industry. In this section, the second objective of the study is addressed: drawing from the core set of papers and the wider literature, an agenda for future research is proposed. The subheadings present a succinct aim for future work which is then expanded in the subsection text.

\subsection{Engage with the unique characteristics of the construction industry}

The complexity of supply chains in construction speaks to the need for both detailed, subdomain specific and sector generic research. The coverage scorecard in Table 3 points to the need for more research in all areas but particularly in taking a holistic approach and addressing relevant subdomains within the sector (lower left quadrant). For example, it remains unknown whether the same principles or the same priorities in operational processes apply to all types of projects. Are there differences between managing the supply chains for residential development where high numbers of units of similar design will be constructed and managing the supply chains for a hospital development, for example? Similarly, there is limited knowledge of the approaches that should be taken for different components and materials - are the processes necessary for the supply chain for steel beams the same as those for the supply chains of window systems? In addition, studies are required which consider issues by the size of the focal organisation.

The construction industry and its constituent supply chains exhibit unique characteristics that differentiate it from other industries. The project-based nature of construction which contrasts with long-term alliances in manufacturing, for example, means that relationships between commissioning firms and suppliers are often one-off, short-term, and potentially adversarial (Ofori, 2000). This works against the SCM ideal of deepening relationships with suppliers to pursue integration of processes (Seuring \& Gold, 2013). An organization in isolation cannot achieve a sustainable product (Loorbach et al., 2010). In particular, the development of trust between firms, which has been identified as crucial to stronger interorganizational relationships (Loorbach et al. 2010), takes time to develop (Pomponi et al. 2015): If projects are ultimately time-limited undertakings, and contracts are likely to be short-term or renegotiated frequently, the context does not encourage the growth of trust (Lu et al., 2016). Within construction, it has been noted that partnering and alliances do not necessarily bring trust and absence of competition (Bossink, 2007; Bresnen \& Marshall, 2000). Indeed, previous research has shown that SCM in construction is often promoted by main contractors in collaboration with large construction clients. Their pursuit of profitability is often to the detriment of other supply chain members, mostly Tier 2 subcontractors who may 
suffer from opportunistic behaviour by main contractors (Alderman and Ivory, 2007). Any effort towards greening the construction supply chain is, thus, first tasked with understanding and resolving those deeply seeded conflicts among supply chain actors to enable the establishment of a more 'collaborative paradigm' (Vachon and Klassen, 2006) for superior environmental performance. Mechanisms to resolve such conflicts among green supply chain actors warrant further investigation. The sheer number of construction supply chain actors is a further challenge (Rezgui and Miles, 2009). With potentially thousands of suppliers on a large construction project, it is difficult for a single contractor to manage the development of relationships and overlapping processes. These challenges, which characterize the construction sector, merit a specific research focus.

\subsection{Take an end-to-end perspective}

As argued above, a holistic, end-to-end and long-term perspective is needed which in practical terms should look for the greatest impacts along the supply chain in order to achieve the greatest and/or most rapid improvement. Although Balasubramanian and Shukla (2017a) suggested that the failings of any one link in the supply chain weaken the supply chain's overall performance, we argue that not all supply chain roles are equal. Supply chain actors may vary dramatically with respect to their environmental impact. Construction supply chains are by no means monolithic, and efforts to green the supply chain cannot be managed as such. Several supply chain actors may adopt green practices faster - either because the benefits of going 'green' are more tangible, or because green practices are readily adaptable and cost-effective - while others may lag behind. Further, although much valuable work has been and is being undertaken on systematic methods for complex decision making (Chen et al 2015; Arroyo et al., 2016), feedback from practitioners demonstrated that the demands in the sector meant that few organisations have the time to develop expertise or time for project team members to apply such expertise (Arroyo et al., 2016). We contend that resources (finance, expertise, time) are best applied to the most damaging aspects across the chain. This points to the value of a 'hotspot' analysis along the whole of the supply chain (Dadhich et al 2015) to facilitate the most effective commitment of resources and potentially quicker beneficial impact. A system of prioritization may be a pragmatic approach to the allocation of resources.

\subsection{Harness other perspectives}

In order to manage changes to supply chain processes, strategic leadership is needed as well as setting operational goals and increasingly challenging objectives (Pagell \& Wu, 2009). Such transitions depend on innovation, creativity and (usually) individual passion (Loorbach et al 2010). Innovation for a sustainable supply chain has been argued to be systematic, complex, collaborative, and to require both internal and external dynamic capabilities (Gao et al. 2017). Such innovations often seek to achieve a positive performance on all three dimensions of sustainability: economic, social and environmental, and look to move from small incremental 
change to radical breakthrough changes in inter-organizational optimization. At this point, a further conceptual integration of innovation theory and SCM with Green SCM is necessary so as to provide further insight into inter-organizational processes, such as inter-organizational knowledge transfer, learning and the development of collaborative relationships between supply chain actors. Research should particularly involve small and medium size (SMEs) enterprises which constitute the major share of construction firms. Research should also examine in more detail the important role played by industry bodies (Wong et al. 2016).

A resource-based view of the firm (Bowen et al., 2001) postulates that environmental management systems and practices are often adopted by firms in the pursuit of increased competitive advantage (Gold et al., 2010). In this perspective, green supply is seen to be shaped by the deployment of a firm's internal supply management capabilities and resources. Thus, greening the supply chain should be supported by sufficient competencies, capabilities, and resources. A resource-based view of the firm could illuminate future research on Green SCM.

A focus on inter-firm capabilities could be informed by a relational view (Gold et al. 2010) which argues that sustainable SCM can bring about sustained inter-firm competitive advantage through the idiosyncratic combination of Inter-firm resources and capabilities emerging from collaborative relationships across an entire supply chain. The development of such novel, complex and difficult-to-imitate inter-firm capabilities through interaction and value co-creation relationships may yield green supply chains which offer a competitive advantage. Hence, this perspective represents an important component of the future research agenda, particularly if examined by adopting rich case study methods that are capable of shedding further light on the interrelated and highly complex relationships between supply chain actors. Empirical exploration and testing could focus on the analysis of how effective supply chain relationships are established, how they can be encouraged, how risk and rewards are distributed, and the conditions that ultimately lead to successful value co-creation and sustained competitive advance across the supply chain through greater environmental performance.

\subsection{Make it practical}

Despite the recommendations for practice, the studies in the review showed little insight into the management competencies, organizational culture, or strategic and operational approaches to managing change over time. The literature has, as yet, relatively little practical guidance to offer organizations seeking to green their supply chain. Scholarly work that is beneficial to practitioners is that which can offer guidance on where to begin Green SCM efforts and the priorities that need to be considered. Bossink's (2007) 8-stage sustainable innovation model offers one such work. Practical guidance could also be developed for 
practitioners on building more collaborative relationships with their suppliers that ultimately support effective communications flow, system integration, and trust. Considerations should be given to the complexity of these relationships, including the volume of products that a supplier may manage, the amount of up-to-date information that is accessible and maintainable, as well as legal issues such as 'who owns this information?' and 'who is liable in cases of error?'. Future research also needs to address the dynamic nature of change: organizations and supply chains cannot change overnight. Guidance on incremental approaches to change is likely to be helpful to practitioners.

\subsection{Keep the ultimate goals in mind}

The concept of 'true sustainability' of Pagell \& Wu (2009) was absent from the construction research reviewed here. Pagell \& Wu (2009) argue that to be truly sustainable, a supply chain should be able to perform profitably indefinitely, with no environmental impact, and with the potential of net environmental benefit as the ideal. Greening a supply chain is a continuous process and the management of greening is ongoing. As one area improves, changing issues, standards, expectations, technologies, data and potential in other areas will warrant attention. Rather than Green Supply Chain Management, it may be more appropriate to refer to Greening the Supply Chain (GtSC) in order to place the emphasis differently, on the challenges of making incremental progress. Given the scale and urgency of environmental problems, radical change may be ideal but in a system as complex as construction supply chains, with hundreds of actor-organizations and thousands of actor-individuals, radical change is rare and most change is progressive and incremental. It is this progressive change that requires active management.

The research reviewed also fell short of considering the wider set of societal stakeholders. Referring to the original definition of sustainable development (Bruntland, 1987), the stakeholders affected by and affecting the environmental performance of construction supply chains include not only today's communities. Inevitably, the ability of future generations to meet the needs of their lifestyle and quality of life is impacted by today's supply chains' consumption of resources and pollution of the environment. Nevertheless, none of the papers in the core sample considered future generations as key stakeholders or contemplated how their needs could be addressed through effective Green SCM. Hence, in future research, consideration must be given not only to clients, construction professionals, labourers, and occupants of the built environment, but also to local and distant communities, future generations and the natural world.

\subsection{Include critical stances}

There is as yet little critical appraisal of Green SCM in construction. Critical stances on SCM have argued that the notion overlooks individual agency and context, in its assumptions that supply chains can be designed or optimized without reference to the people, cultures, and 
norms within which they operate (Adamides et al., 2012). Issues of power - inherent in all social interactions (Russell, 1938) - are not examined (Faria, 2004). The assumption that goals among suppliers and the dominant organization are aligned is rarely discussed (Adamides et al., 2012). A positivist approach underlies much previous work, with a default assumption of instrumentalism - that GSMC is undertaken for reasons of enhancing profit margins and/or reputation (Gold and Schleper, 2017). Such a position reduces human actors to the onedimensional pursuit of 'rational utility', overlooking consideration of ethics and societal good, including the understanding of 'true sustainability' as discussed above. A recent paper, published after the SLR, offers valuable development of theoretical framings of Green SCM in construction from a realist perspective (Balasubramanian \& Shukla, 2018) but may nevertheless be critiqued on its underlying theoretical paradigm. The notion of drivers and barriers aligns with Lewin's (1951) concept of force field analysis but stops short of recognizing the forces as mutually interdependent and constituent of norms of action (Burnes, 2004). A binary differentiation of forces internal and external to a firm is also problematic as the boundary between an organization and its external environment is not distinct (Myers et al., 2012). The field of Green SCM in construction will clearly benefit from drawing on critical approaches to sustainable supply chain management to broaden, deepen and enrich intellectual exploration of its application and implications.

\section{Conclusion}

This study applied a systematic literature review to offer a comprehensive and rigorous perspective on Green SCM research published before the end of August 2017 in the construction industry. The scholarly work reviewed is of significant value in advancing Green $\mathrm{SCM}$ in construction. The reviewed sources have been described according to the publication outlet, date of publication, geographic setting, methods used, tools and techniques, conceptual definition, and the role of stakeholders. The practical implications deriving from the papers were also underlined. Synthesis has resulted in a proposed categorization of research approaches and a comprehensive definition of Green SCM in construction was also developed. The review opens interesting opportunities for future research and underlines the need for an end-to-end perspective, engagement with the unique characteristics of the industry, a focus on the ultimate goals of environmental sustainability, and on gaps in practical guidance, use of insights from relevant theoretical perspectives, and expansion to include critical stances.

Green SCM may hold the competitive edge in the $21^{\text {st }}$ century's construction industry as increased ethical and environmental awareness among communities as well as construction clients grows. The pressure on the construction industry to transform itself to address its role in environmental and climate damage will only increase. It is hoped that the research agenda proposed some timely insights and reminders which may prove useful in future research in this vibrant and vital research domain. 


\section{References}

Note: core papers included in the systematic literature review are indicated with *

*Abdul Ghani, N. M. A., Egilmez, G., Kucukvar, M. \& Bhutta, M. K., 2017. From green buildings to green supply chains: An integrated input-output life cycle assessment and optimization framework for carbon footprint reduction. Management of environmental quality, 28, 4, 532-548.

Adamides, E. D., Papachristos, G. \& Pomonis, N., 2012. Critical realism in supply chain research: Understanding the dynamics of a seasonal goods supply chain. International journal of physical distribution and logistics management, 42, 10, 906-930.

*Adawiyah, W. R., Pramuka, B. A. \& Najmudin, J. D. P., 2015. Green supply chain management and its impact on construction sector small and medium enterprises (SMEs) performance: A case of Indonesia. International business management, 9, 6, 10181024.

Ahi, P. \& Searcy, C., 2013. A comparative literature analysis of definitions for green and sustainable supply chain management. Journal of cleaner production, 52, August 2013, 329-341.

*Ahmadian FF, A., Rashidi, T. H., Akbarnezhad, A., \& Waller, S. T., 2017. BIM-enabled sustainability assessment of material supply decisions. Engineering, Construction and Architectural Management, 24, 4, 668-695.

*Aho, I. 2013. Value-added business models: linking professionalism and delivery of sustainability. Building Research \& Information, $41,1,110-114$.

*Albino, V. \& Berardi, U.,2012. Green Buildings and Organizational Changes in Italian Case Studies. Business Strategy and the Environment, 21,6, 387-400

Alderman, N. and Ivory, C.,2007. 'Partnering in major contracts: Paradox and metaphor', International Journal of Project Management, 25, 4, 386-393.

*Arroyo, P., Tommelein, I. D. \& Ballard, G., 2016. Selecting globally sustainable materials: A case study. Journal of construction engineering and management, 142, 2, 05015015.

* Balasubramanian, S., 2014. A structural analysis of green supply chain management enablers in the UAE construction sector. International journal of logistics systems and management, 19, 2, 131-150.

*Balasubramanian, S. \& Shukla, V., 2017a. Green supply chain management: an empirical investigation on the construction sector. Supply Chain Management, 22,1, 58-81.

*Balasubramanian, S. \& Shukla, V., 2017b. Green supply chain management: the case of the construction sector in the United Arab Emirates (UAE) Production planning and control, 28,14, 1116-1138.

Balasubramanian, S., \& Shukla, V., 2018. Environmental supply chain management in the construction sector: theoretical underpinnings. International Journal of Logistics Research and Applications, 21, 5, 502-528.

Ballou RH, Gilbert SM, Mukherjee A., 2000, New managerial challenges from supply chain opportunities. Industrial Marketing Management, 29,1, 7-18. 
*Blengini, G. A. \& Garbarino, E., 2010. Resources and waste management in Turin (Italy): The role of recycled aggregates in the sustainable supply mix. Journal of cleaner production, 18, 10-11, 1021-1030.

*Bohari, A., Skitmore, M., Xia, B. \& Teo, M., 2017. Green-oriented procurement for building projects: Preliminary findings from Malaysia. Journal of cleaner production 148, April 2017, 690-700.

Bossink, B. A. G., 2007. The inter-organizational innovation processes of sustainable building: A Dutch case of joint building innovation in sustainability. Building and Environment, 42, 12, 4086-4092.

Bowen FE, Cousins PD, Lamming RC, Faruk AC., 2001. The role of supply management capabilities in green supply. Production and Operations Management 10, 2, 174-189.

Bresnen, M. and Marshall, N., 2000, Partnering in Construction: A Critical Review of Issues, Problems and Dilemmas, Construction Management and Economics, 18, 2, 229-237.

Brewerton P, Millward L., 2001. Organizational Research Methods. Sage Publications: London.

Briner, R. B. \& Denyer, D., 2012. Systematic review and evidence synthesis as a practice and scholarship tool. In: Rousseau, D. M., ed.) The Oxford handbook of evidence-based management. Oxford: Oxford University Press. pp. 112-129.

Brundtland, G., 1987. Our common future: Report of the 1987 World Commission on Environment and Development. United Nations, Oslo.

Burnes, B., 2004. Kurt Lewin and the planned approach to change: A re-appraisal. Journal of management studies, 41,6, 977-1002.

Carter, C. R., \& Rogers, D. S., 2008. A framework of sustainable supply chain management: moving toward new theory. International journal of physical distribution \& logistics management, 38, 5, 360-387.

*Chen, P.-C., Liu, K.-H. \& Ma, H.-W., 2017. Resource and waste-stream modelling and visualization as decision support tools for sustainable materials management. Journal of cleaner production, 150, May 2017, 16-25.

*Chen, R.-H., Lin, Y. \& Tseng, M.-L., 2015. Multicriteria analysis of sustainable development indicators in the construction minerals industry in China. Resources policy, 46, 1, 123133.

*Chileshe, N., Rameezdeen, R., Hosseini, M. R., Lehmann, S. \& Udeaja, C., 2016. Analysis of reverse logistics implementation practices by South Australian construction organisations. International Journal of Operations \& Production Management, 36, 3, 332-356.

Climate Analytics, 2018) Paris Agreement ratification tracker. Accessed on 5/8/2018. http://climateanalytics.org/briefings/ratification-tracker.html

*Dadhich, P., Genovese, A., Kumar, N. \& Acquaye, A., 2015. Developing sustainable supply chains in the UK construction industry: A case study. International Journal of Production Economics, 164, June 2015, 271-284.

*Dainty, A. R. J. \& Brooke, R. J., 2004. Towards improved construction waste minimisation: A need for improved supply chain integration? Structural survey, 22, 1, 20-29.

*Da Rocha, C. G. \& Sattler, M. A., 2009. A discussion on the reuse of building components in Brazil: An analysis of major social, economical and legal factors. Resources, 
conservation and recycling, 54, 2, 104-112.

Ehrenfeld, J. R., 1995. Design for the environment: a new framework for strategic decisions. Environmental Quality Management, 4, 4, 37-51.

*Elbarkouky, M. M. G. \& Abdelazeem, G., 2013. A green supply chain assessment for construction projects in developing countries. WIT transactions on ecology and the environment, 179, 2013, 1331-1341.

European Union, 2015) Construction and demolition waste (CDW) [Available online from http://bit.ly/1ERulE1.]

*Faleschini, F., Zanini, M. A., Pellegrino, C., \& Pasinato, S., 2016. Sustainable management and supply of natural and recycled aggregates in a medium-size integrated plant. Waste Management, 49, March 2016, 146-155.

Faria, A. 2004. Theorising networks from a critical realist standpoint: the discovery of power and contextual issues within and outside 'networks'. In: Fleetwood, S. \& Ackroyd S. (eds.) Critical realist applications in organisation and management studies. London: Routledge. Pp. 211-233.

Fulford, R. and Standing, C., 2014. 'Construction industry productivity and the potential for collaborative practice', International Journal of Project Management, 32, 2, 15-326.

Gao, D., Xu, Z., Ruan, Y. Z., \& Lu, H., 2017. From a systematic literature review to integrated definition for sustainable supply chain innovation (SSCl). Journal of cleaner production, 142, 4, 1518-1538.

Gold, S. \& Schleper, M. C., 2017. A pathway towards true sustainability: a recognition foundation of sustainable supply chain management. European management journal, $35,4,425-429$.

Gold, S., Seuring, S., \& Beske, P., 2010. Sustainable supply chain management and interorganizational resources: a literature review. Corporate social responsibility and environmental management, 17, 4, 230-245.

Gough, D., Oliver, S. \& Thomas, J., 2012. An introduction to systematic reviews, London, Sage.

Green, S. \& May, S., 2005. Lean construction: arenas of enactment, models of diffusion and the meaning of "leanness". Building research and information, 33, 6, 498-511.

*Hendrickson, C. \& Horvath, A., 2000. Resource use and environmental emissions of US construction sectors. Journal of construction engineering and management, 126,1, 3844.

HM Government., 2013. Construction 2025. Industrial Strategy: Government and Industry in Partnership. The Stationary Office, London, UK.

*Hsueh, S.-L. \& Yan, M.-R., 2013. A multi-methodology contractor assessment model for facilitating green innovation: The view of energy and environmental protection. The scientific world journal, 2013, 624340.

Ibn-Mohammed, T., Greenough, R., Taylor, S., Ozawa-Meida, L., \& Acquaye, A., 2013. Operational vs. embodied emissions in buildings $-A$ review of current trends. Energy and Buildings, 66, November 2013, 232-245.

IPCC (Intergovernmental Panel on Climate Change, 2012, Special Report on Renewable Energy Sources and Climate Change Mitigation, online: https://www.ipcc.ch

Irizarry, J., Karan, E. P., \& Jalaei, F., 2013. Integrating BIM and GIS to improve the visual monitoring of construction supply chain management. Automation in Construction, 
31, 241-254.

*Irland, L. C., 2007. Developing markets for certified wood products: Greening the supply chain for construction materials. Journal of industrial ecology, 11,1, 201-216.

Ive, G. and Murray, A., 2013. Trade Credit in the UK Construction Industry: An Empirical Analysis of Construction Contractor Financial Positioning Performance, London: Department for Business, Innovation, and Skills.

*Ketikidis, P. H., Hayes, O. P., Lazuras, L., Gunasekaran, A. \& Koh, S. C. L., 2013. Environmental practices and performance and their relationships among Kosovo construction companies: A framework for analysis in transition economies. International journal of services and operations management, 14,1, 115-130.

*Kim, M. G., Woo, C., Rho, J. J. \& Chung, Y., 2016. Environmental capabilities of suppliers for green supply chain management in construction projects: A case study in Korea. Sustainability, Switzerland, 8,1, 1-17.

*Kucukvar, M., Egilmez, G., \& Tatari, O., 2014. Evaluating environmental impacts of alternative construction waste management approaches using supply-chain-linked life-cycle analysis. Waste Management \& Research, 32,6, 500-508.

*Kucukvar, M., Egilmez, G., \& Tatari, O., 2016. Life cycle assessment and optimization-based decision analysis of construction waste recycling for a LEED-certified university building. Sustainability, 8,1, 89.

Lambert DM, Cooper MC. 2000. Issues in supply chain management. Industrial Marketing Management 29,1, 65-83.

Lewin, K., 1951) Field Theory in Social Science, New York: Harper and Row.

Loorbach, D., van Bakel, J. C., Whiteman, G., \& Rotmans, J., 2010. Business strategies for transitions towards sustainable systems. Business Strategy and the Environment, 19, 2, 133-146.

Lucon, O., Urge-Vorsatz, A., Zain Ahmed, H., Akbari, P., Bertoldi, L. F. \& Al., E., 2014. Buildings. In Climate Change 2014: Mitigation of Climate Change. Contribution of Working Group III to the Fifth Assessment Report of the IPCC. 5th Assessment. Cambridge: Intergovernmental Panel on Climate Change.

Lu, P., Qian, L., Chu, Z., \& Xu, X., 2016) Role of opportunism and trust in construction projects: empirical evidence from China. Journal of management in engineering. 32, 2,05015009.

*Mahamadu, A. M., Mahdjoubi, L., \& Booth, C. A., 2013. Challenges to digital collaborative exchange for sustainable project delivery through building information modelling technologies. WIT Transactions on Ecology and the Environment, 179, 547-557.

Martin, C., 2017) New York City to require big buildings to cut carbon emissions. Accessed 5.8.2018 https://www.bloomberg.com/news/articles/2017-09-14/new-york-city-torequire-big-buildings-to-cut-carbon-emissions

Myers, P., Hulks, S. \& Wiggins, L., 2012. Organizational change: perspectives on theory and practice, Oxford, Oxford University Press.

*Nasir, M. H. A., Genovese, A., Acquaye, A. A., Koh, S. C. L. \& Yamoah, F., 2017. Comparing linear and circular supply chains: A case study from the construction industry. International journal of production economics, 183, Part B, 443-457. 
*Neppach, S., Nunes, K. R. \& Schebek, L., 2017. Organizational environmental foot printing in German construction companies. Journal of cleaner production, 142, 1, 78-86.

*Ofori, G., 2000. Greening the construction supply chain in Singapore. European Journal of Purchasing and Supply Management, 6, 3-4, 195-206.

Pagell, M. \& Shevchenko, A., 2014. Why research in sustainable supply chain management should have no future. Journal of supply chain management, 50,1, 44-55.

Pagell, M. \& Wu, Z., 2009. Building a more complete theory of sustainable supply chain management using case studies of 10 exemplars. Journal of supply chain management, 45, 2, 37-56.

Pomponi, F., Fratocchi, L., \& Rossi Tafuri, S., 2015. Trust development and horizontal collaboration in logistics: a theory based evolutionary framework. Supply Chain Management: An International Journal, 20,1, 83-97.

Pryke, S., 2009. Construction supply chain management: Concepts and case studies, Vol. 3. John Wiley \& Sons, Chester.

Rezgui, Y., and J. Miles., 2009. "Exploring the Potential of SME Alliances in the Construction Sector." Journal of Construction Engineering and Management 136, 5, 558-567.

${ }^{*}$ Rizzi, F., Frey, M., Testa, F., \& Appolloni, A., 2014. Environmental value chain in green SME networks: the threat of the Abilene paradox. Journal of cleaner production, 85, December 2014, 265-275.

*Ruparathna, R., \& Hewage, K., 2015. Sustainable procurement in the Canadian construction industry: current practices, drivers and opportunities. Journal of Cleaner Production, 109, December 2015, 305-314.

Russell, B., 1938. Power: A new social analysis, London, George Allen \& Unwin Ltd.

Saad, M., Jones, M., \& James, P., 2002. A review of the progress towards the adoption of supply chain management (SCM) relationships in construction. European Journal of Purchasing \& Supply Management, 8, 3, 173-183.

*Salzer, C., Wallbaum, H., Lopez, L. F., \& Kouyoumji, J. L., 2016. Sustainability of Social Housing in Asia: A Holistic Multi-Perspective Development Process for Bamboo-Based Construction in the Philippines. Sustainability, 8, 2, 151.

Sarkis, J., Zhu,Q.,Lai, K.,, 2011) An organizational theoretic review of green supply chain management literature, International Journal of Production Economics, 130,1, 1-15.

*Sarkis, J., Meade, L. M. \& Presley, A. R., 2012. Incorporating sustainability into contractor evaluation and team formation in the built environment. Journal of cleaner production, 31, August 2012, 40-53.

*Sertyesilisik, B., 2016. Embending Sustainability Dynamics in the Lean Construction Supply Chain Management. YBL Journal of Built Environment, 4,1, 60-78.

*Seth, D., Shrivastava, R. L. \& Shrivastava, S., 2016. An empirical investigation of critical success factors and performance measures for green manufacturing in cement industry. Journal of manufacturing technology management, 27, 8, 1076-1101.

Seuring, S. \& Gold, S., 2013. Sustainability management beyond corporate boundaries: from stakeholders to performance. Journal of cleaner production, 56, October 2013, 1-6.

Seuring S, Müller M., 2008a. Core Issues in Sustainable Supply Chain Management - a Delphi Study. Business Strategy and the Environment, 17, 8, 455-466.

Seuring, S., \& Müller, M., 2008b. From a literature review to a conceptual framework for 
sustainable supply chain management. Journal of cleaner production, $16,15,1699$ 1710.

*Shen, L., Zhang, Z., \& Zhang, X., 2017. Key factors affecting green procurement in real estate development: A China study. Journal of Cleaner Production, 153, June 2017, 372-383.

*Udawatta, N., Zuo, J., Chiveralls, K., \& Zillante, G., 2015. Attitudinal and behavioural approaches to improving waste management on construction projects in Australia: benefits and limitations. International Journal of Construction Management, 15, 2, 137-147.

United Nations Framework Convention on Climate Change, 2015. Adoption of the Paris agreement. Online: http://unfccc.int/resource/docs/2015/cop21/eng/l09r01.pdf

United Nations Environment, 2017. Towards zero-emission efficient and resilient buildings: Global Status Report 2017. Available online: www.worldgbc.org

*Uttam, K., \& Roos, C. L. L., 2015. Competitive dialogue procedure for sustainable public procurement. Journal of Cleaner Production, 86, January 2015, 403-416.

Vachon S, Klassen RD., 2006. Extending green practices across the supply chain. The impact of upstream and downstream integration. International Journal of Operations \& Production Management 26, 7, 795-821.

Vrijhoef, R., \& Koskela, L., 2000. The four roles of supply chain management in construction. European journal of purchasing \& supply management, 6, 3-4, 169-178.

Walton, S.V., Handfield, R.B., Melnyk, S.A., 1998. The green supply chain: integrating suppliers into environmental management processes. Journal of Supply Chain Management. 34, 2, 2-11.

*Wong, J., Chan, J. \& Wadu, M., 2016. Facilitating effective green procurement in construction projects: An empirical study of the enablers. Journal of Cleaner Production, 135, November 2016, 859-871.

*Woo, C., Kim, M. G., Chung, Y. \& Rho, J. J., 2016. Suppliers' communication capability and external green integration for green and financial performance in Korean construction industry. Journal of cleaner production, 112, Part 1 January 2016, 483-493.

*Zhou, P., Chen, D. \& Wang, Q., 2013. Network design and operational modelling for construction green supply chain management. International journal of industrial engineering computations, 4, 1, 13-28.

Zhu, Q. \& Sarkis, J., 2006. An inter-sectoral comparison of green supply chain management in China: drivers and practices. Journal of cleaner production, 14, 5, 472-486.

*Zou, P. X. W. \& Couani, P., 2012. Managing risks in green building supply chain. Architectural engineering and design management, 8, 2, 143-158.

*Zuo, K., Potangaroa, R., Wilkinson, S., \& Rotimi, J. O., 2009. A project management prospective in achieving a sustainable supply chain for timber procurement in Banda Aceh, Indonesia. International Journal of Managing Projects in Business, 2, 3, 386-400. 